\title{
INDEX OF SUBJECTS AND COUNTRIES
}

GENERAL ISSUES

Religions and Pbilosopby, I $16-$ I 20, 283-288, 480-482.

Social and Political Science, I 20-I 28, 289-297, 482-49I

History, 1 28-1 31 , 297-301, $491-493$.

Contemporary Issues, I 3 I-I 35 , 30I-307, 493-497.

CONTINENTS AND

COUNTRIES

Africa (For North Africa see also: Asia), I35-138, 307-309, 497-498.

Algeria, $136,307-308$.

Central African Federation, I $37,308,497-498$.

Egypt, 308.

French West Africa, I 37.

Ghana, 137, 498 .

Nigeria, 137, 308-309.

Sudan, 498.

Tunisia, 138, 309 .

Union of South Africa, 138 , $309,498$.

America, 138-141, 309-3I8, 499-504.

Canada, 499.
Cuba, 499.

Guatemala, 499.

Mexico, 138.

United States of America, I 3 8-I 4I, 3I0-3 I 8, 499-504

Asia, I4I-I46, 31 8-325, 504511 .

Burma, 3 I9.

Ceylon, 505.

China, 142-143, 319-320, 505-506.

India, I43-I44, 320-321, 507-509.

Indonesia, 144, 321, 509.

Iraq, I44-1 45, 322 .

Israel, $145,322,509$.

Japan, 145, 322-324, 510 SII.

Jordan, 146.

Korea, 5 II.

Pakistan, 146.

Turkey, 354, 5 I .

Union of Socialist Soviet Republics - Russia (Asian Territories), $\mathrm{SI}$ I.

Vietnam, 324.

Australia and Oceania, I46, 324-325, 512.

Australia, 324.
New Zealand, 146, 324-325, sI2.

Europe, 174-175, 325-360, 51 2-546.

Austria, 149.

Belgium, 326-327, 5 14.

Bulgaria, I49.

Czechoslovakia, 149, 327.

Eire, 327-328, 5 I4.

Finland, 149.

France, I 50-1 54, 328-334, $5 \times 4-520$.

Germany, I 54-161, 334-345, $520-528$.

Great Britain, I62-165, 346-348, 528-531.

Hungary, 166, 532 .

Italy, I66-167, 348-35 I. 53 I536.

The Netherlands, $167,35 \mathrm{I}$, $536-538$.

Poland, I68-169, 352-354, $538-539$.

Spain, $170,540$.

Switzerland, 170, 540-541. Union of Socialist Soviet Republics - Russia, $x 7^{0-}$ $174,354-360,541-545$. Yugoslavia, I75, 545-546. 